the case she said that it was chorea. The movements on close observation are seen to be not quite the same as in chorea, but affect the trunk more than the limbs, producing a shuffling or shifting movement; they affect the arms and legs only slightly and the face not at all. When she tries to button her jacket she makes steady, quiet and persevering efforts to succeed, not at all like the violent and tearing efforts made by a child suffering from chorea. A well-marked lateral curvature of the spine is present, occupying the dorsal region. The column curves threequarters of an inch to the right of the middle line from the fourth to the tenth dorsal vertebræ. The cervical and lumbar regions are straight and there is no tenderness anywhere over the spine. I tested her cutaneous sensibility and considered it to be exaggerated to heat and cold. She is very sensitive to tickling of the soles of the feet and bursts into a lond laugh when they are tickled. There is no difficulty, nor has there ever been any, with the bladder and rectum. When placed on the floor on her back and told to get up she raises herself into the sitting position, then gets on her knees and assumes the upright position with a spring. The whole process is performed quickly and without trouble, but she is very unsteady when the erect posture is finally reached and would fall if not assisted. There have been no lightning pains complained of at any time tither in the lower limbs or elsewhere. When told to close her eyes and to put her forefinger on the tip of her nose she fails, missing the tip by about an inch. She protrudes her tongue quite straight, but her speech is slow, thick and drawling. The pupils react to light and accommodation; the optic discs are perfectly normal and there is slight nystagmus, which becomes more apparent when she accommodates for near objects. Romberg's symptom is not marked; indeed, I think she stands just as well with her eyes closed as open. The intellectual faculties are normal; in fact, she is a bright-looking girl and answers questions promptly. She is interested in all that goes on in the ward and amuses herself with the other children. Her general health is good and she eats and sleeps well.

Remarks. - In this interesting case I think it will be admitted that the symptoms are sufficient to warrant me in naming the case as one of Friedreich's disease, but the hereditary part of the history broke down at every turn. I made inquiries extending to previous generations and could find no history of anything of the kind in the family on either side, neither club-foot, spinal curvature nor peculiarity of gait. It is worthy of note that in this case there is a strong family history of tubercle in both the father and mother. May not tubercle, therefore, be the cause of postero-lateral sclerosis of the cord in some cases? I have not seen this point mentioned and would like to know if it has been noted. I regret that I was unable to photograph the spinal and pedal deformities; however, the Figures $9,12,13,14$ and 16 in Dr. Byrom Bramwell's "Atlas of Clinical Medicine," vol. i., pages 39 and 40, represent very closely the condition of the parts in this case.

Belfast.

\section{ON SOME POINTS IN THE DIAGNOSIS OF SMALL-POX AS ILLUSTRATED IN THE WARRINGTON EPIDEMIC.}

Bx J. GUEST GORNALL, M.A., M.B. Cantab., M.R.C.S., I.R C.P. LOND.,

ASSISTANT MEDICAL OFFICER OF HEALTH FOR WARRINGTON AND MEDICAL SUPERINTENDENT OF THE SMALL-POX HOSPITAL

Is speaking of the diagnosis of small-pox I do not propose to cover the whole ground of the many points that may arise in the discussion of the matter, but simply to give some details of my own experience, which will, I hope, prove both useful and interesting.

INITIAL RASHES.

Though the cases of small-pox, of which I have seen upwards of 600 , mostly came under observation after the true eruption had begun to appear, and consequently there must have been some in which any initial rash had disappeared before admission to hospital, I have seen several varievies of these most important aids to diagnosis and in each instance have kept records. I believe that these rashes are a comparatively rare feature of small-pox, modified or unmodified, though the danger of -not being alive to their signification will be well illustrated by a case which I shall give below.
From my own experience I would divide initial rashes into the following classes: (1) Scarlatiniform; (2) morbilliform; (3) urticarial; and (4) petechial.

1. Scarlatiniform rashes, as far as my own observation goes, are general in their distribution, precede severe and often rapidly fatal attacks, and not uncommonly, though not invariably, are an early feature of purpura variolosa. The following cases of the kind have come under my notice : (1) A man aged thirty-nine, having one vaccination mark, died suddenly in a syncopal state after a two days' illness, in which a universal scarlet rash preceded extravasations all over the body. An undoubted case of small-pox was traced to this patient. (2) A man aged thirty-five, alcoholic, and who had one foreate cicatrix of one-ninth of a square inch area, twelve days after encoffining the body of a person dead of small-poz, was admitted with an intense red rash all over the body. A few subcuticular papules could be seen and were readily felt on the forehead. He died about twelve hours after admission, but exhibited no sign of bæmorrhage. A simila scarlatiniform rash preceded the true eruption also in two cases of fatal confluent small-pox.

2. Erythematous rashes of a morbilliform type, as far as I have seen, occur in cases which must be placed in a very different category from those with scarlatiniform ones. I have only seen six instances of this kind. Of these I saw two at their own homes at a very early stage of the disease and ordered their immediate removal ; three of the patients came in on the day of the onset, and the other developed the smallpox whilst in hospital. I give particulars of these in a tabulated form :-

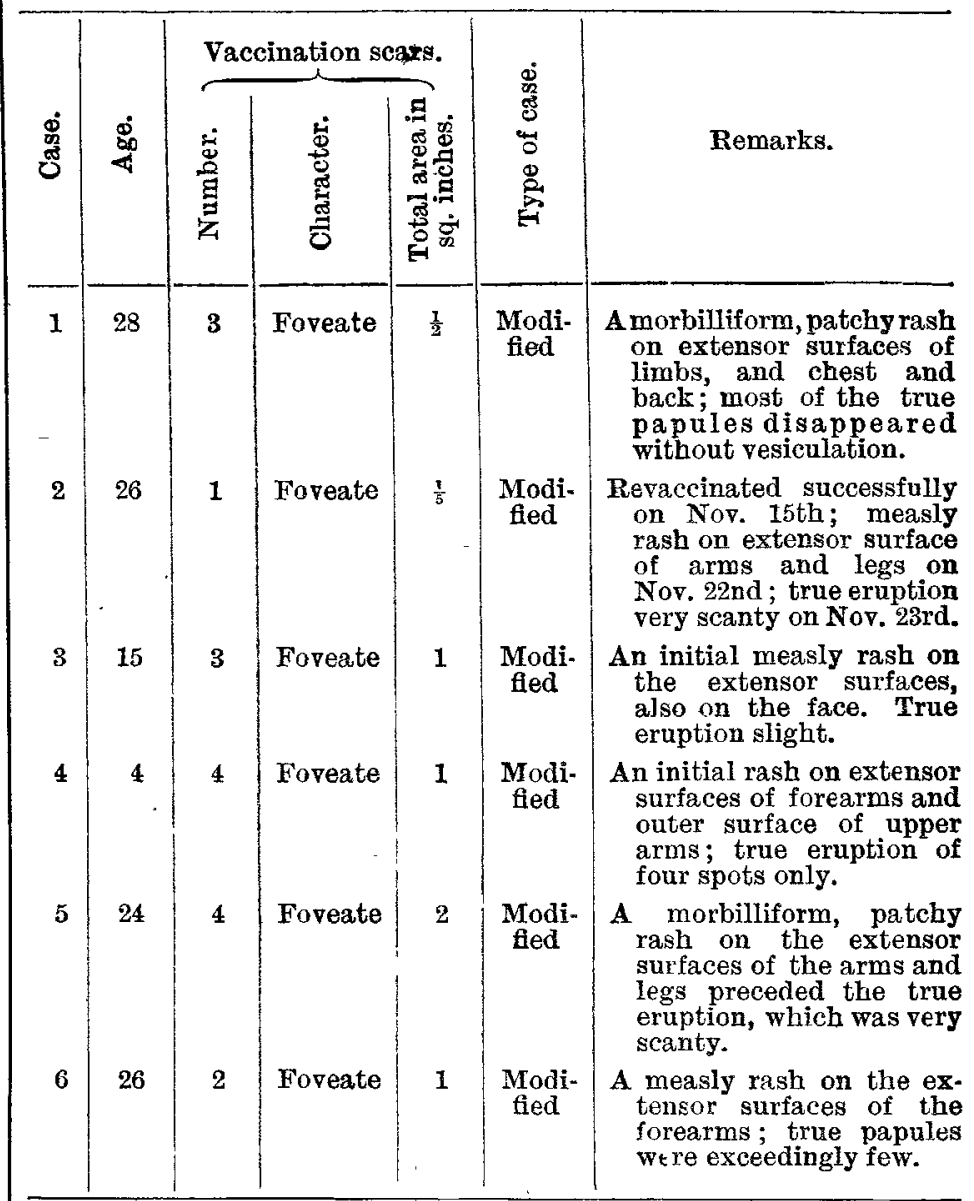

From the above cases, the character of which, I am inclined to think, must represent the general type of those in which morbilliform rashes occur, it seems that (1) these rashes may be somewhat irregular in distribution, though their most characteristic situations are the face and the extensor surfaces of the limbs, but they do not find their favourite positions in the groins and axillæ as in the cases of other initial eruptions which will be mentioned later; (2) they occur only in discrete cases of a much modified characterthe only patient amongst those who suffered from them and whose foveate area was unsatisfactory was, it will be seen, successfully revaccinated a week before the rash. In some old descriptions a "cutaneous efflorescence" is said sometimes to precede the outbreak of the general eruption in inoculated small-pox, and the same was noticed to occur in the very mild cases of the natural disease which became common after the introduction of vaccination. It has been 
held that erythematous rashes are characteristic of varioloid. Our experience seems to lead to the conclusion that those of a morbilliform type are characteristic of attacks much modified by vaccination.

3. Urticarial rashes. - Urticaria has such specific exciting causes that it would appear desirable from a clinical point of view to treat it separately in this connexion. So far as I have seen no initial rashes of this type are described in the text-books, but I have seen two cases, and heard of others in this neighbourhood, where such a thing occurred. The first was a case of small-pox due to infection introduced into a general hospital. A boy aged ten, in good general health but an in-patient for some eye affection, was seized with pain in the back and head, and the same evening was found to have a temperature of 103. I was asked to look at him and found him to present an urticarial rash on the extensor surfaces of the forearms and legs, in front of the axilla, and about the groin and lower part of the abdomen. This eruption consisted of large wheals with some inflammatory redness about them, attended by considerable itching, and appearing and disappearing from time to time. From the special sitnation of this rash and the outbreak of other cases of small-pox in the place at the same time I was able to make a diagnosis that was confirmed by the appearance of the true eruption on the following day. I have since the above seen a similar condition in an unvaccinated youth aged seventeen, who was admitted to the Warrington Hospital with discrete small-pox. In this the true papules were already appearing and the remains of the urticaria consisted of a patch in front of the left axillary flexure only. This came out on the day of the onset, Feb. 10th, the true eruption appearing on the day of admission to hospital, Feb. 12th. It would seem that an urticarial eruption in the situations above described is diagnostic of small-pox. A more generalised urticaria occurring in a person in a house, from which a case of small-pox had recently come, almost led me to a mistaken diagnosis, but was found to depend on dietetic irregularities.

4. Petechial initial rashes, as distinguished from the extravasation of malignant cases, I have seen in five instances, all occurring in characteristic situations and all preceding severe attacks of small-pox. I give some particulars of these cases in a tabulated form :-

\begin{tabular}{|c|c|c|c|c|c|c|}
\hline \multirow[b]{2}{*}{ 弯 } & \multirow[b]{2}{*}{$\stackrel{8}{\stackrel{8}{4}}$} & \multicolumn{3}{|c|}{ Vaccination scars. } & \multirow{2}{*}{ 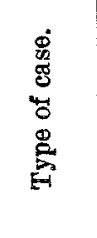 } & \multirow[b]{2}{*}{ Remarks. } \\
\hline & & 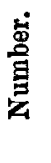 & 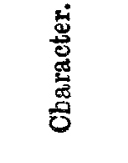 & 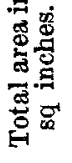 & & \\
\hline 1 & 24 & 2 & Plain & $\frac{1}{4}$ & $\begin{array}{l}\text { Con- } \\
\text { fluent }\end{array}$ & $\begin{array}{l}\text { Marked petechial rash } \\
\text { about groins and lower } \\
\text { part of abdomen. A very } \\
\text { severe case. }\end{array}$ \\
\hline 2 & 36 & 2 & - & - & $\begin{array}{l}\text { Dis- } \\
\text { crete }\end{array}$ & $\begin{array}{l}\text { Had a similar rash to the } \\
\text { above and had old lupus } \\
\text { scars on the face, over } \\
\text { which alone the true erup- } \\
\text { tion was confluent. A } \\
\text { somewhat severe case. }\end{array}$ \\
\hline 3 & 41 & 2 & Foveate & 1 & $\begin{array}{l}\text { Con- } \\
\text { fluent }\end{array}$ & $\begin{array}{l}\text { A fatal case ; there were } \\
\text { a few scattered, fading } \\
\text { petechia about the groins } \\
\text { and the extensor surfaces } \\
\text { of the arms on admission; } \\
\text { these, except for their } \\
\text { grouping in these situa- } \\
\text { tions, could nnt be dis- } \\
\text { tinguished fi om old flea- } \\
\text { bites. }\end{array}$ \\
\hline 4 & 24 & 1 & Foveate & $\frac{1}{3}$ & $\begin{array}{l}\text { Con: } \\
\text { fluent }\end{array}$ & $\begin{array}{l}\text { Intense petechial rashes } \\
\text { about the hips, gruins, } \\
\text { lower part of abdomen, } \\
\text { axille and around the } \\
\text { nipples ; over these parts } \\
\text { the rash was confluent, } \\
\text { over the rest of the body } \\
\text { it was discrete. Notified } \\
\text { as variola nigra, but the } \\
\text { attack proved to be } \\
\text { mitigated, the patient } \\
\text { getting up in a week after } \\
\text { admission. }\end{array}$ \\
\hline 5 & 24 & 2 & Plain & $\frac{3}{8}$ & - & $\begin{array}{l}\text { Petechial rash about groins } \\
\text { and lower part of the } \\
\text { abdomen. This was a } \\
\text { fatal case, complicated } \\
\text { with broncho-pneumonia. }\end{array}$ \\
\hline
\end{tabular}

A petechial rash, then, appears to precede only cases of considerable severity, though not necessarily fatal ones. It wilt be observed that the vaccinated state of all the above patients was distinctly inferior to that of those in whom morbilliform rashes occurred, if one takes into consideration both the age and the number and character of the scars. In the third of the above instances the discovery of fading petechiæ grouped in characteristic situations certainly suggests the possibility of rashes of limited extent easily escaping observation. The mitigation of the attack of the fourth probably was a consequence of her having been raccinated in infancy, taking into consideration her age as well as ber cicatrices in comparison with the others. In one case of purpura variolosa, which $I$ had the opportunity of observing from 2 very early stage, it was a matter of interest to note that the extravasations began to appear as petecniz about the flexures of the groins and axillæ which are the chosen seats of the rashes that have just been mentioned.

I have referred above to a case arising in consequence of infection entering a general hospital. The method of introduction here was of such a kind as to illustrate several points of interest and importance. I am enabled to furnish some details thereof. A man aged twenty-one applied one afternoon about 4 P. M. on account of retention of urine. As he appeared to be very ill he was taken in; his temperature was then $994^{\circ}$. On further examination he was found to present a scarlatiniform rash geverally dis. tributed. At $6 \mathrm{P}$ M. the temperature was $100.4^{\circ}$, at $10 \mathrm{P}$.M it was $99.8^{\circ}$, and at midnight he died. There was no evidence of stricture; subsequently it was found that a petechial rash. had developed about the groins. At the end of a fortnight nine inmates of the hospital, four of them nurses, who came in contact with the above patient or his bedding or clothes. were removed to the local small-pox hospital, and a same time the mother of the man was taken there from her home. Fortunately ali of these recovered, but the incident illustrates the extreme difficulty of early diagnosis and of preventing an extension of the disease without vaccination. Retention of urine is a symptom that has been known occasionally to complicate the onset of small-pox and is doubtless an indication of the centres for micturition being involved in that affection of the spinal cord of which pain in the back is probably a sign.

\section{The Diagnosis of SMall-Pox FRom otmer Dismase:}

The greater number of cases of mistaken diagnosis with which I have had to deal have been in patients suffiering from varicella. One case, which was of considerable interest, have reported. ${ }^{1}$ Three have since then been admitted, which, on examination, I regarded as being most undoubtedly chicken-pox. They were as follows :-

CASE 1.-A boy aged seven, having three foreate cicatrices of an aggregate area of four-fifths of a square inch. The rasb appeared on May 12th. He was admitted on the 13th and found to have an eruption consisting of about thirty pocks on the face, a fair number on the body, and a very few scatteres ones on the limbs. Some few of these were umbilicated, but most had the pearly lustre and absence of induration which are characteristic of chicken-pox. There was no fever after admission. He was vaccinated at once, witb the result that considerable papules developed at the points of insertion of the lymph, but did not reach the stage of vesiculation.

CAsE 2.-A girl aged eleven, said to have been vaccinated, but having no marks. The rash began to appear on May 23rd and continued to come out during the following day. She was admitted to hospital on the $26 \mathrm{th}$, when the appearance presented was very suggestive of varicella, especially on account of the different stages in which the pocks were. She. was vaccinated with four insertions of calf lymph. This was attended by complete success, though with the tendency to sloughing so common after the use of animal vaccine, and no sign of small-pox ever appeared. The engraving, which is. from a photograph, shows this case very well; the other patient in it was an unvaccinated child five years of age, who was admitted with confluent small-pox, from which, after a severe illness, it fortunately recovered.

CASE 3. - A boy aged four was admitted on May 23rd with what appeared to bear every evidence of being chicken-pox; but as he possessed four foveate cicatrices of a little more than one square inch I deemed it unnecessary to vaccinate him. There was no fever on admission, and the child, appearing to be 
quite well, was allowed to get up, the temperature being taken regularly. The original eruption soon disappeared, leaving the usual slight redness about the situation of the pocks, and the child continued in good health until June 1st, on the evening of which day it appeared to be languid, the temperature being $986^{\circ} \mathrm{F}$. It was accordingly kept in bed and the following notes of the subsequent progress of the case were taken: "June 2nd: Morning temperature 99.8 ; complains of pain in the chest and back of the head; face slightly Alushed; on extensor surfaces of forearms and outer surfaces of arms a patchy erythematous eruption, having a somewhat irregular, though not shotty, feel to the touch. Frening temperature $102.8^{\circ}$; delirious. - $3 \mathrm{rd}$ : Morning temperature $100^{\circ}$; the eruption on the arms has gone, but a papule has appeared on the left cheek.-4th: Temperature $99.8^{\circ}$; a slight papular rash on the extensor surfaces of the arms; three papules now show themselves on the face and one on the back of the right shoulder.-5th: Temperature normal. The rash on the and of the disease on admission having been really varicella in the second the success of vaccination affords an undoubted proof of my diagnosis in a patient with whom the third of the series may be profitably contrasted.

The above cases but add to the already strong evidence in favour oi the essential difference between variola and varicella-a distinction so easily to be put to the test by vaccina. tion. Three other cases of considerable interest have been admitted whose disease was not small-pox. The first was a case of acne, chiefly on the forehead and upper arm, which followed successful revaccination after a month's interval, some constitutional disturbance due to an axillary abscess consequent on vaccination aiding in the formation of a mistaken opinion. The second was in a woman subject to chronic rheumatism, who on admission was found to have erythema nodosum as well as numerous small papules on the arms. She was at once revaccinated with success, the eruption

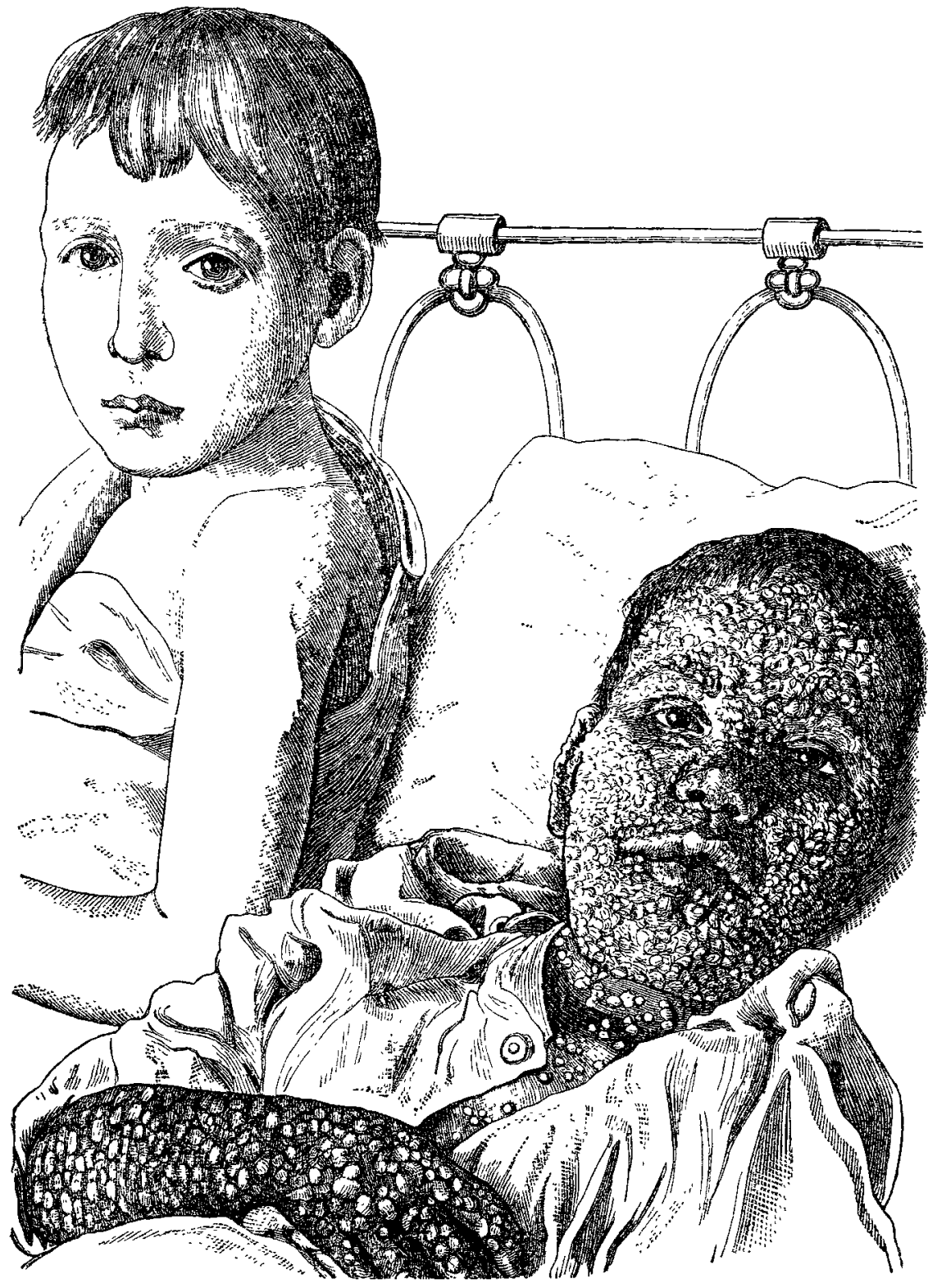

arms has gone, but four papules, three on the face and one tion. This seems either to have been a part of rheumatic on the back of the right shoulder, have reached the suppuEative stage, a small vesicle with opaque contents now appearing on each." From this time no further symptoms were observed and the child quickly regained its normal condition-one of good health. I believe that this was an ur doubted case of modified small-pox in which an initial rash of morbilliform type preceded the true eruption, which litter on the arms was only evanescent. I have included this child amongst the patients with morbilliform rashes given above. The failure of so excellent and recent vaccination to prevent small-pox entirely may conceivably be ascribed to the special exposure to the poison of the disease. The child was in the same ward with confluent cases in all stages. Of the other two cases of chicken-pox, in the first the slight papulation at the point of inoculation is probably an indication of extremely slight susceptibility to vaccinia

origin or to bave been a salicylate rash, for she had been taking large doses of the drug. The third was the case of a strong and healthy man, with vaccination marks of good quality on both arms. On coming into hospital he was found to have a temperature of $103^{\circ}$, a foul tongue, and on the arms, thighs and legs numerous fairly large papules, somewhat oval in shape and livid in colour. These were unattended with itching and devoid of any sign of vesiculation. There was no history of an onset such as small-pox generally has. The progress of the case during the next two or three days helped to increase the doubts I already had and he was accordingly vaccinated, an operation which I repeated in two days, but which was on neither occasion attended with success. The rash, however, was gone in less than a week, leaving only a slight desquamation, and the patient at the same time regained his ordinary health. 
Whatever the reason of my want of success in vaccinating this patient, what followed shows that one should not be in a hurry to act on one's opinion in such a case. I became now inclined to believe that after all he must have had a very modified kind of variola and he was discharged a fortnigh after admission. He returned in a few days with an attack of small-pox which, though appearing likely to be of a severe confluent type, proved abortive and fortunately, as far as I can ascertain, caused no other attacks in the town. I do not feel prepared to give any name to the illness with which this man was admitted and which led to a mistaken diagnosis.

Warrington.

\section{ACUTE PERICARDITIS, ENDOCARDITIS AND PNEUMONIA:}

COMPLICATIONS OF A CASE OF ACUTE RHEUMATISM; RECOVERY.

Bx N. HAY FORBES, L.R.C.P. LOND., M.R.C.S. ENG., FORMERLY ON THE MEDICAL STAFF OF H.M. ARMY.

In The Lancet of July 22nd Dr. D. B. Lees discusses the treatment of pericarditis in an interesting and instructive paper, the chief points of clinical and practical interest being, firstly, "the proper treatment" of the disease; secondly, the importance of bearing in mind "the seriousness of the results of pericarditis in children and young adults" ; and, lastly, the therapeutic value of "the local persistent application of cold" to the region of the heart. The following case presents certain features both of clinical and diagnostic interest, which I shall endeavour to demonstrate, directing attention to the following points in particular: (1) an almost entire absence of joint symptoms ; (2) pneumonia, an additional complication, increasing the gravity of the case ; (3) dilatation of both ventricles of the heart, being more marked in the left than in the right; (4) ayspnoea, which was never very urgent; (5) enlargement of the thyroid gland; (6) the differential diagnosis between pericarditis and commencing aortic disease; and (7) treatment, in which the cardinal points were absolute rest, counter-irritation, alkalies, salicylates, digitalis and a nutritious dietary.

On March 30th, 1892, I was called to see the patient, a thin, delicate-looking girl sixteen years of age. She was suffering from pains in the chest and shortness of breath on exertion; her face was swollen, the result of a carious tooth. Her parents are living and fairly healthy, the father being subject to bronchitis in the winter; the patient is one of a large family, some of whom present a typically strumous aspect. The patient has not had any serious illnesses beyond those incidental to childhood. In December, 1892, she had an attack of rheumatism in the joints, but was not confined to bed, continuing at her daily work. Since then she had enjoyed fairly good heaith until the middle of March, when she had a chill whilst hard at work house-cleaning. She also stated that she had been feeling out of sorts, had slept badly, and had suffered from weakness and aching of the imbs during the previous week. The catamenia appear ed at the age of fifteen; they were irregular; they last appeared the day before she was taken ill (March 29th). The bowels apparently were quite regular. The tongue was moist and clean, with the exception of the back part, which was furred. The appetite was extremely poor. The complexion was pale, sallow and earthy looking. The skin was smooth, hot and dry. The feet were cold and clammy. On examination the chest was resonant over both lungs anteriorly, expansion being fairly good. The breath sounds were harsh and somewhat wavy in character. No crepitation or other abnormal sound was audible. The area of dulness of the heart was increased, extending from the level of the third interspace to the level of the sixth rib; its action was rapid and tumultuous, the rhythm was cantering, the impulse was diffused and the apex beat was indistinct. The sounds in general were muffled. Over the centre of the cardiac area a diffused, harsh, rasping to-and-fro friction sound was distinctly audible, being apparently intensified towards the apex, the beat of which was systolic in rhythm. This rub could be very perceptibly felt on light palpation in the fourth interspace half an inch to the left of the manu-
brium sterni. There was no definite bulging of the præ- cordial region or appreciable widening of the intercostat paces. The pulse was 120, rapid and compressible but regular. The temperature (in the mouth) was $103.2^{\circ} \mathrm{F}$. The urine was of a pale orange colour, being slightly turbid, but without deposit; acid ; its specific gravity was 1025 ; there wais no albumen. The patient was put to bed in a well warmed and properly ventilated room. Linseed-meal poultices to the eft side of the chest, a hot-water bottle to the feet and a mixture of salicylate of soda, tincture of aconite (minim doses) and tincture of orange, to be taken every four hours, were ordered. The knees and ankles were swathed in cotton-wool and flannel bandages. The following day the temperature was $103^{\circ}$ and the pulse was 112 . At the heart's apex a soft mitral systolic bruit was audible. The patient had not slept. much owing to the pain she suffered. The bowels had acted. April 1st.-The pulse is 104. The pericardial friction sound is less pronounced, but the endocardial bruit is quite distinctly discerned and can be traced in the direction of the mid-axillary line. The patient has slept better; the skin is perspiring. Nourishment-milk, plain and with soda-wateris given at regular intervals.

2nd.-At the base of the heart an aortic systolic hæmic bruit is heard. A mixture of bicarbonate of soda, bicarbonate of potassium, iodide of potassium, tincture of nux vomica and compound tincture of cardamoms, to be taken every four hours, was prescribed, the bowels acting freely with the aid of salts and senna. A cantharides plaster was applied over the middle of the præcordia with markedly beneficial effect. ${ }^{1}$

10th. - The temperature is $102^{\circ}$. The patient does not suffer so much pain in the chest and at present there is no urgent dyspnoa; she is resting comfortably in the horizontal position. Over the left cheek an exythematous blush has appeared; there is no herpes. The respiration (22 per minute) is laboured. The pericardial rub can be more distinctly heard and its limits more accurately defined.

13th. - The patient has slept better during the last two nights. There is some symmetrical lateral enlargement of the thyroic gland, the swelling being roughly about the size of a small orange, but not painful nor tender on pressure. On examining: the interior of the throat nothing abnormal can be detected. The cardiac dulness extends now from the level of the second interspace to the level of the sixth rib, measuring laterally from $2 \frac{1}{2}$ in. to 3 in. The temperature is $102^{\circ}$. The face is flushed. The dyspnoea is somewhat increased, but not to the extent of orthopnœa. There is no irregularity in the pulse. The pain in the joints is very slight. She perspires, but not profusely.

15th. - This morning the patient was seen in consultation with Dr. Ranking, to whom I am indebted for some valuable suggestions. It was then noted that the cardiac dulness could be clearly mapped out, its shape and daily condition having been carefully watched. It extended laterally into the left flank and in front (to the right) as far as the centre or nearly to the right margin of the manubrium sterni. There was nnmistakable evidence of dilatation of the left ventricle with inflammation of its endocardium and a systolic mitral bruit. The right ventricle was dilated, but not in a marked degree. The præcordial friction sound was quite distinct, coupled with signs of sero-fibrinous effusion (hypopericardium). At the left posterior base, a finger's breadth below the scapular angle, the percussion note was dull; there were impaired resonance and diminished expansion. Several fine moist crepitation râles were audible. There were the general physical signs of pneumonia in the middle lobe of the left lang-a group of signs rendering the differential diagnosis between the dulness of the pericardial effusion and that of pneumonic consolidation somewhat difficult to diagnose. The breathing was hurried; there was scarcely any typical rusty expectoration. The patient had been taking twenty-grain doses of salicylate of soda with a teaspoonful of effervescing citro-tartrate of sodium three times a day and latterly a separate mixture of sulphate of quinine and juice of digitalis. Counter-irritation to the præcordia was continued. The nourishment consisted chiefly of milk with two teaspoonfuls of brandy taken every two hours.

16th. - The patient has slept well. The tongue is moist and coated with brown fur, the skin is cooler. A hæmic basic bruit is still audible and a mitral bruit is heard far into the axilla, the heart's impulse is heaving and diffused.

18th. - The respiration is more tranquil, the dyspnoea is less and the pectoral pain is disappearing. The bowels have acted well. There is an increase in the quantity of the

1 Cf. Fagge's Practice of Medicine, vol. ii., p. 100. 